\title{
APLIKASI KEGIATAN ORMAWA POLSRI BERBASIS ANDROID HYBRID DENGAN FRAMEWORK IONIC PADA POLITEKNIK NEGERI SRIWIJAYA
}

\author{
Meivi Kusnandar ${ }^{1}$, Ahmad Ari Gunawan Sepriansyah2), Rika Sadariawati3), dedy rusdyanto4) \\ 1,2,3,4 Jurusan Manajemen Informatika, \\ Politeknik Negeri Sriwijaya
}

\begin{abstract}
Abstrak
Tujuan penulisan penelitian ini adalah untuk membuat Aplikasi kegiatan Ormawa pada Politeknik Negeri Sriwijaya Palembang dimana pihak dari Ormawa Polsri ingin menampilkan informasi kegiatan mereka baik yang proker dan non proker setiap tahunnya dan juga sosialisasi dari kegiatan tersebut. Pengembangan aplikasi android ini menggunakan framework lonic.Proses yang digunakan untuk mendesain sistem ini adalah membuat rancangan dengan menggunakan Unifed Modelling Language (UML) dan menggunakan bahasa pemrograman Android serta databaseMySQL. Sistem ini selanjutnya akan diupload sehingga setiap anggota ormawa dapat mendownload serta menginstall aplikasi ini pada smartphone mereka. Dengan dibuatnya sistem ini diharapkan dapat mempermudah pihak ormawa untuk mensosialisasi setiap event yang akan mereka adakan dengan mengakses aplikasi ini.
\end{abstract}

Keyword: aplikasi, android, mysql

\section{Pendahuluan}

Politeknik Negeri Sriwijaya adalah sebuah lembaga pendidikan vokasi di kota Palembang yang sudah mempunyai mahasiswa yang cukup banyak.sebagai lembaga pendidikan tinggi Politeknik Negeri Sriwijaya mempunyai bidang kemahasiswaan yang mengelola setiap kegiatan mahasiswa yang ada pada lembaga ini.

ORMAWA Politeknik Negeri Sriwijaya adalah sekumpulan mahasiswa yang berkumpul dan memiliki kedudukan resmi di lingkungan POLSRI serta mendapat pendanaan kegiatan kemahasiswaan dari institusi Polsri atau kementrian/lembaga.Negara (Persero) Tbk yang beralamat di Jalan Rimba Kemuning Lorong Ogan No. 26-28 Palembang Melakukan kegiatan yang tidak bertentangan dengan Undang undang Dasar 1945 dan Pancasila serta selaras dengan visi dan misi Polsri. Kegiatan yang dilaksanakan terdiri dari empat bidang dimana masing masing terdapat pembimbing kegiatan yang ditugaskan untuk membina dan membimbing kegiatan agar berkualitas dan berdaya guna. Empat bidang yang menjadi ranah kegiatan mahasiswa tersebut terdiri dari :
1. Bidang Penalaran, Keahlian dan Keprofesian

2. Bidang Minat Bakat dan Kegemaran

3. Bidang Kesejahteraan Mahasiswa

4. Bidang Kewirausahaan dan Kreativitas Mahasiswa

Organisasi Mahasiswa di Polsri terdapat Majelis

Permusyawaratan Mahasiswa (MPM) yang merupakan lembaga legislatif perwakilan mahasiswa dan Badan Eksekutif Mahasiswa (BEM) yang dipimpin oleh Presiden Mahasiswa serta 9 (Sembilan) Himpunan Mahasiswa Jurusan (HMJ) yang dipimpin Gubernur Mahasiswa. Pemilihan dan pergantian kepengurusan dilaksanakan setiap setahun sekali pada ajang Pemilihan Umum Raya Keluarga Mahasiswa (PEMIRA KM).

Setiap kegiatan dari ORMAWA mereka selalu mensosialiasikan kepada seluruh mahasiswa di setiap jurusan baik kegiatan berupa lomba, seminar ataupun workshop yang melibatkan mahasiswa Polsri.Dalam mensosialisasi kegiatan Ormawa mereka selalu mendatangi setiap jurusan dan cara ini selalu memakan waktu dan sedikit menggangu kegiatan belajar karena mereka mendatangi setiap kelas di masing-masing jurusan. 
Kendala ini sudah lama berlangsung pada setiap akan diadakannya suatu kegiatan yang melibatkan mahasiswa dari seluruh juruan di Politeknik Negeri Sriwijaya.

Untuk mengatasi masalah ini penulis akan membuat aplikasi yang akan membantu pihak Ormawa dalam mensosialisasikan kegiatan mereka. Aplikasi yang dibuat akan menampilkan seluruh informasi tentang kegiatan ormawa dilengkapi dengan menu untuk chatting untuk setiap anggota ormawa sehingga mereka lebih mudah dalam berkoordinasi untuk setiap kegiatan yang akan dilaksanakan.

\section{Perumusan Masalah}

Aplikasi Kegiatan Ormawa berbasis android hybrid dengan framework android dirumuskan dalam permasalahan penelitian sebagai berikut:

1) Belum adanya aplikasi yang bisa memberikan informasi kepada setiap anggota ORMAWA untuk kegiatan yang akan dilaksanakan baik internal maupun eksternal kampus.

2) Pemanfaatan teknologi yang belum maksimal untukmeningkatkan pelayanan informasi kepada mahasiswa atau masyarakat umum untuk lebih mudah mengakses informasi yang disesuaikan dengan kebutuhan pengurus dan Anggota ORMAWA.

\section{Luaran Penelitian}

1) Luaran Wajib:

Publikasi IImiah di Jurnal Nasional terakreditasi (ber ISSN).

2) Luaran Tambahan:

Aplikasi Kegiatan Ormawa yang dapat dijalankan pada Aplikasi Smartphone minimal Android Kitkat.

\section{Tujuan Penelitian}

Padalaporan akhir penelitian ini diambil dari literature pustaka baik yang dari website, artikel ilmiah. Sedangkan penulusuran data melalui pakar dilapangan masih berlangsung, mengingat fakta dilapangan cukup banyak prosedur pengambilan data tentang calon pelanggan yang tersebar di wilayah palembang. Adapun tujuan adalah sebagai berikut:
1) Membangun sebuah aplikasi kegiatan ormawa pada Organisasimahasiswa di Politeknik Negeri Sriwijaya Palembang.

2) Dapat menyampaikan informasi kegiatan mahasiswa kepada seluruh anggota ormawa tentang kegiatan-kegiatan yang akan dilaksanakan ke depan.

\section{Manfaat Penelitian}

Adapun manfaat dari penelitian ini adalah:

a) Untuk membantu para anggota ormawa untuk sharing kegiatan yang akan dilaksanakan oleh unit mahasiswa.

b) Dengan Aplikasi ini mahasiswa juga bisa saling bicara melalui fitur chat tentang informasi apa saja tentang semua kegiatan yang akan dilaksanakan oleh ormawa dan seluruh unit yang terlibat.

\section{Tinjauan Pustaka 4.1 Program Aplikasi}

Menurut Budiharto (2013:5) menyimpulkan Program Aplikasi adalah program yang berjalan di komputer tersendiri ( Stand Alone) dari mulai program yang simpel sampai dengan program besar dan rumit.

Menurut Sutabri (2012:147) menyatakan bahwa 'Aplikasi adalah alat terapan yang difungsikan secara khusus dan terpadu sesuai kemampuan yang dimilikinya.

\subsection{Android}

Menurut Nazruddin Safaat H (2011) Android adalah sebua sistem operasi untuk perangkat mobile berbasis linux yang mencangkup sitem operasi, middleware dan aplikasi.

\subsection{Features Android}

Nazruddin Safaat H (2011) mengemukakan Features yang tersedia pada platform

android saat ini antara lain :

a. Framwork aplikasi yang mendukung pergantian komponen dan reusable. 
b. Mesin Virtual Dalvik berjalan diatas linux kernel dan dioptimalkan untuk perangkat mobile.

c. Integrated browser berdasarkan open source engine webkit.

d. Grafis yang di optimalkan dan didukung oleh liblary grafis $2 \mathrm{D}$ yang terkostumisasi, grafis $3 \mathrm{D}$ berdasarkan spesifikasi open GL ES 1.0 (opsianal akselerasi hardware).

e. SQL lite untuk meyimpan data .

f. Media support yang mendukung audio, videoa dan gambar.

g. GSM telephone (tergantung dari hadware).

h. Bluetooth, EDGE, 3G, dan wifi (tergantung hardware).

i. Dukungan dari perangkat tambahan: android dapat memanfaatkan kamera, layar sentuh, accelerometers, magnetometers, GPS, Oreantasi, scalling, akselerasi grafik 3D.

j. Multi-touch : kemampuan layaknya handset modern yang dapat menggunakan dua jari atau berinteraksi dengan perangkat.

k. Lingkungan development yang lengkap dan kaya termasuk perangkat emulator, tools untuk debugging profil dan kinerja memory dan plugin untuk Eclipse IDE.

\subsection{Android Arsitektur}

Menurut Safaat (2011) Dalam prosesnya pencarian lokasi menggunakan GPS di mobile Android dapat menggunakan dua API dalam Android SDK yaitu:

a. Location Manager (API Maps)

b. Location Provider (API Location)

\subsection{Software yang Digunakan}

\section{Eclipse}

Menurut Nazruddin Safaat H (2011) Eclipse adalah sebuah IDE (Integrated Development Environment) untuk mengembangkan perangkat lunak dan dapat dijalankan di semua platform (platform-independent) (Nazruddin SH,2011).

\section{Java}

Menurut Budi et al. (2010) Java adalah bahasa pemrograman yang dapat dijalankan di berbagai komputer termasuk telepon genggam Bahasa ini awalnya dibuat oleh James Gosling saat masih bergabung di Sun Microsystems saat ini merupakan bagian dari Oracle dan dirilis tahun 1995.

\section{Android SDK (Software Development Kit)}

Menurut Nazruddin Safaat H (2011) Android SDK adalah tools API (Application Programming Interface) yang diperlukan untuk mulai mengembangkan aplikasi pada platform Android menggunakan bahasa pemrograman Java.

\section{ADT (Android Development Tools)}

Menurut Nazruddin Safaat H (2011) ADT adalah kepanjangan dari Android Devlopment Tools yang menjadi penghubung antara IDE Eclipse dengan Android SDK. ADT atau lebih di kenal dengan plugin Eclipse, plugins ini yang dapat membuat eclipse dapat membuat project yang berbasis Android.

\section{Aplikasi Hybrid}

Intuisi dari aplikasi hybrid adalah menanamkan aplikasi mobile HTML5 ke dalam konten aplikasi native. Aplikasi hybrid merupakan kombinasi dari kelebihan yang dimiliki antara aplikasi web dan aplikasi native. Aplikasi hybrid mengkonversi aplikasi web mobile HTML5 ke aplikasi native smartphone yang ditargetkan. Konversi aplikasi web mobile ke dalam aplikasi native memerlukan dukungan perangkat lunak spesifik semacam framework pengembangan aplikasi mobile.

Kelebihan aplikasi hybrid adalah tahap pengembangannya yang relatif mudah karena memanfaatkan standar teknologi web. Aplikasi hybrid dapat berjalan pada hampir semua platform mobile yang dituju, artinya aplikasi hybrid dapat didistribusikan secara aplikasi native menuju ke platform mobile yang ditargetkan oleh pengembang. Distribusi aplikasi yang secara native memungkinkan aplikasi hybrid untuk dapat mengakses fitur-fitur perangkat keras seperti kamera, wifi, kalender dan file.

\section{Aplikasi Hybrid pada Platform Android}

Aplikasi Hybrid adalah gabungan antara aplikasi native dan aplikasi web.

Pengembangan aplikasi hybrid menggunakan HTML5, JavaScript, CSS3 danlonic Framework 
yang di dalamnya terdapat compiler Apache Cordova.

\section{Ionic Framework}

Ionic adalah kerangka ponsel HTML5 dengan fokus pada kinerja yang memanfaatkan akselerasi hardware dan tidak memerlukan pihak ketiga seperti JS library. Ionic bekerja bersama-sama dengan Angular.js untuk membangun sebuah aplikasi interaktif.

Aplikasi hybrid pada dasarnya ialah website kecil yang berjalan di shellbrowser, sebuah aplikasi yang memiliki akses ke lapisan platform asli dari sebuah device. Aplikasi hybrid memiliki banyak manfaat jika dibandingkan denganaplikasi native, khususnya dalam hal mendukung platform dan kecepatan pengembangan.

Ionic dilengkapi dengan elemen UI mobile dan layout yang mirip dengan SDK asli pada iOS atau Android. Ionic memerlukan Apache Cordova untuk menjalankan aplikasi. lonic juga menggunakan AngularJS untuk melakukan banyak fungsi inti dari framework.

\section{Metode Penelitian}

\subsection{WaktuDanTempat}

Pelaksanaan penelitian dilakukan selama 6 (Enam) bulan dengan menggunakan penelitian kuantitatif. Lokasi penelitian yang dilakukan oleh penulis dilaksanakan di unit kegiatan mahasiswa Politeknik Negeri Sriwijaya Palembang.

\subsection{Metode Pengumpulan Data}

Emzir (2010:37-61), adapun metode pengumpulan data yang dilakukan penulis dalam rangka mendukung tercapainya pengumpulan data dengan melakukan kegiatan sebagai berikut :

\section{1) Observasi}

Observasi didefinisikan sebagai perhatian yang terfokus terhadap kejadian, gejala, atau sesuatu' dengan maksud menafsirkan, mengungkapkan faktor-faktor penyebab dan menemukan kaidahkaidah yang mengaturnya. Disini penulis mengamati atas apa yang dikerjakan oleh setiap UKM (Unit Kegiatan Mahasiswa) pada Politeknik Negeri Sriwijaya.

2) Wawancara / interview

Wawancara adalah teknik yang paling sederhana terdiri atas sejumlah pertanyaan yang dipersiapkan oleh penulis yang diajukan pada seseorang mengenai topik penelitian secara tatap muka, dan penulis merekam jawabanjawaban sendiri. Penulis mengadakan interview di UKM (Unit Kegiatan Mahasiswa) pada Politeknik Negeri Sriwijaya.

3) Dokumen

Berbagai macam dokumen telah penulis cermati. Dari mengumpulkan data dan informasi yang diperlukan dengan menggunakan literal-literal kepustakaan meliputi, membeli buku, meminjam buku, browsing diinternet, hingga mengumpulkan data-data tentang kegiatan-kegiatan apa saja yang akan dilaksanakan oleh Unit Kegiatan Mahasiswa (UKM) di Politeknik Negeri Sriwijaya Palembang.

\section{Alat dan Bahan}

\subsection{Alat}

Untuk menghasilkan sebuah aplikasi yang dapat menghasilkan informasi yang cepat, tepat dan akurat dibutuhkan elemen-elemen dari sistem komputer sebagai alat bantu. Adapun alat tersebut terdiri dari perangkat keras (hardware) dan perangkat lunak (software), yaitu:

\section{1) Perangkat Keras (Hardware)}

Perangkat keras adalah peralatan di sistem komputer yang secara fisik terlihat dan dapat digunakan. Adapun perangkat keras (hardware) yang digunakan, yaitu:

a. Table PC berupa laptop dengan spesifikasi Table PC berupa laptop dengan spesifikasi AMD Dual Core E1-1200 with Radeon Graphics $1.4 \mathrm{GHz}$
b. $1.4 \mathrm{GHz}$
c. RAM 2GB
d. Harddisk 320GB
e. Printer Epson L110
f. Flashdisk Toshiba 32GB
g. Modem GSM

2) Perangkat Lunak (Software) 
Perangkat lunak adalah program yang berisi perintah-perintah untuk melakukan pengolahan data. Adapun perangkat lunak yang digunakan yaitu:

a. Microsoft Windows 8.1.

b. Adobe Dreamweaver CS5 digunakan untuk membangun aplikasi.

c. MySQL digunakan untuk medesain database dari program aplikasi yang akan dibangun.

d. Eclipse digunakan untuk membuat program berbasis Android

\subsection{Bahan}

Penulis menggunakan beberapa bahan berupa data dalam penelitian ini diantaranya sebagai berikut:

1) Informasi tentang kegiatan-kegiatan dari unit Kegiatan Mahasiswa (UKM) di Politeknik Negeri Sriwijaya Palembang.

2) Buku-buku yang berkaitan dengan pembuatan sistem.

\section{Tahapan dalam Penelitian}

Pada tahap penyelidikan awal, penulis mengamati tentang apa yang dibutuhkan dan diharapkan dari sistem aplikasi ini. Oleh karena itu penulis membangun Aplikasi Kegiatan Ormawa ini dengan ketentuan sebagai berikut:

1) Aplikasi Kegiatan Ormawa ini harus mempunyai form login sebagai tindakan Autentifikasi (security) terhadap sistem yang menentukan siapa saja yang dapat menggunakan sistem.

2) Aplikasi Kegiatan Ormawa ini menyediakan form-form sesuai dengan kebutuhan admin, sehingga diharapkan dapat membantu Ormawa dalam menyebarkan informasi kegiatan yang akan dilaksanakan.

3) Sistem ini mampu mempermudah dalam proses pengolahan data kegiatan Ormawa Polsri.

\section{Metode Pengembangan Sistem}

\section{Scope Definition (Definisi Lingkup)}

Pada tahap ini dilakukan pengumpulan informasi yang akan diteliti tingkat feasibility dan ruang lingkup proyek. Hal ini dilakukan untuk menemukan inti dari masalah-masalah yang ada (problems), kesempatan untuk meningkatkan kinerja organisasi (opportunity), dan kebutuhan - kebutuhan baru yang dibebankan oleh pihak manajemen atau pemerintah (directives).

2. Problem Analysis (Analisis Permasalahan)

Pada tahap ini akan diteliti masalah-masalah yang ada pada sistem yang berjalan, Dalam hal ini yang dihasilkan dari tahapan preliminary investigation adalah kunci utamanya. Hasil dari tahapan ini adalah peningkatan performa sistem yang akan memberikan keuntungan dari segi bisnis perusahaan. Hasil lain dari tahapan ini adalah sebuah laporan yang menerangkan tentang problems, causes, effects, dan solution benefits.

3. Requirements Analysis (Analisis Kebutuhan)

Pada tahap ini akan dilakukan pengurutan prioritas dari kebutuhan-kebutuhan bisnis yang ada. Tujuan dari tahapan ini adalah mengidentifikasi data, proses dan antarmuka yang diinginkan pengguna dari sistem yang baru.

4. Logical Design (Desain Logis)

Tujuan dari tahapan ini adalah mentransformasikan kebutuhan-kebutuhan bisnis dari fase requirements analysis kepada sistem model yang akan dibangun nantinya. Dengan kata lain pada fase ini akan menjawab pertanyaanpertanyaan seputar penggunaan teknologi (data, process, interface) yang menjamin usability, reliability, completeness, performance, dan quality yang akan dibangun di dalam sistem.

\section{Decision Analysis (Analisis Keputusan)}

Pada tahap ini akan akan dipertimbangkan beberapa kandidat dari perangkat lunak dan keras yang nantinya akan dipilih dan dipakai dalam implementasi sistem sebagai solusi atas problems dan requirements yang sudah didefinisikan pada tahapan-tahapan sebelumnya.

\section{Physical Design (Desain Logis)}

Tujuan dari tahapan ini adalah mentransformasikan kebutuhan bisnis yang direpresentasikan sebagai logical design menjadi physical design yang nantinya akan dijadikan sebagai acuan dalam membuat sistem yang akan dikembangkan. Jika di dalam logical design tergantung kepada berbagai solusi teknis, maka physical design merepresentasikan solusi teknis yang lebih spesifik.

\section{Constuction and Testing}

Setelah membuat physical design, maka akan dimulai untuk mengkonstruksi dan melakukan tahap uji coba terhadap sistem yang memenuhi kebutuhan-kebutuhan bisnis dan spesifikasi desain. Basis data, program aplikasi, dan antarmuka akan mulai dibangun pada tahap ini. Setelah dilakukan uji 
coba terhadap keseluruhan sistem, maka sistem siap untuk diimplementasikan.

8. Installation and Delivery

Pada tahap ini akan dioperasikan sistem yang telah dibangun. Tahapan ini akan dimulai dengan men-deploy software hingga memberikan pelatihan kepada user mengenai penggunaan sistem yang telah dibangun.

\section{Tampilan Aplikasi}

\section{a. Tampilan Halaman Home}

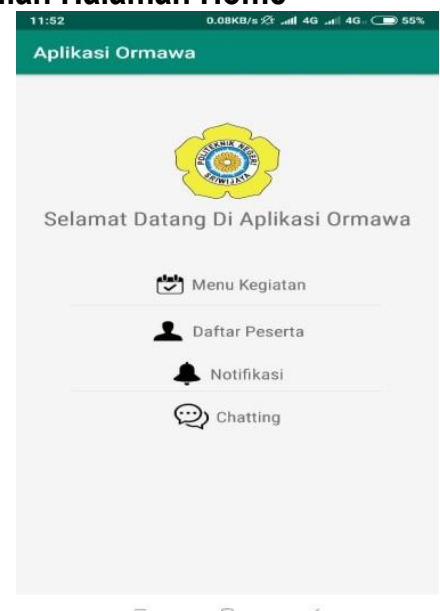

Gambar 1. Tampilan Halaman Home

\section{b. Tampilan Login}

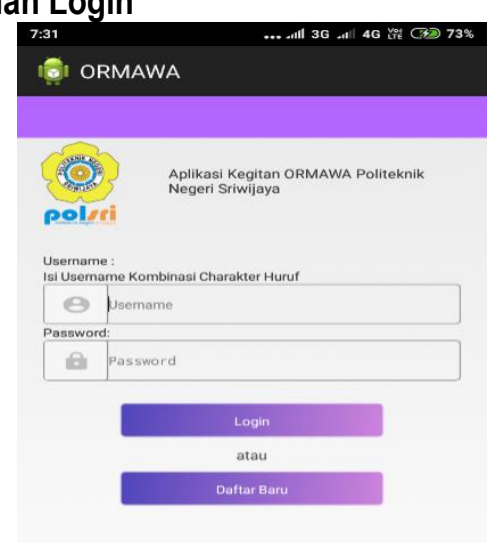

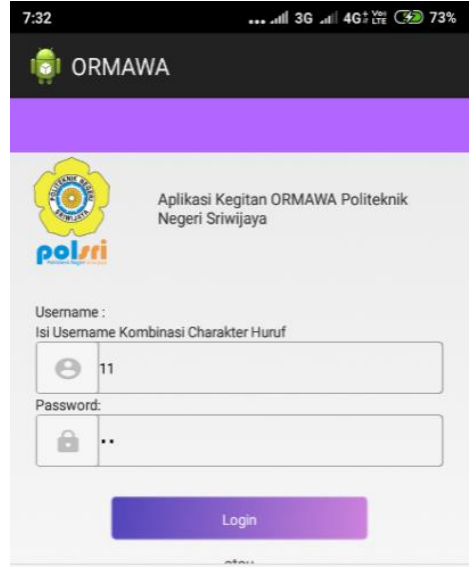

Gambar 2. Tampilan Login

c. Halaman Group Siswa

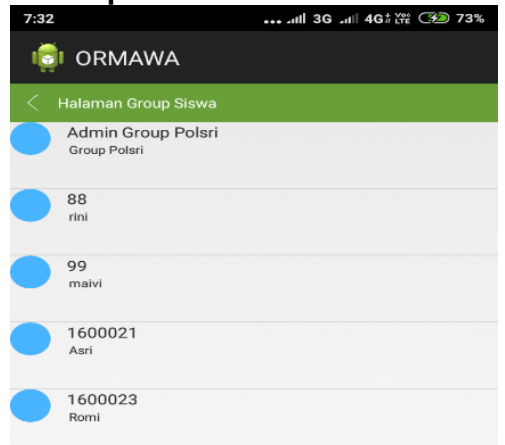

Gambar 3. Tampilan Group

d. Tampilan Informasi Kegiatan

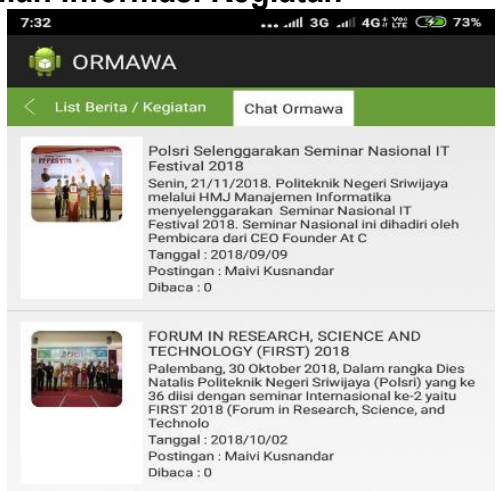

Gambar 4. Tampilan Informasi Kegiatan 


\section{e. Tampilan Pendaftaran Peserta}

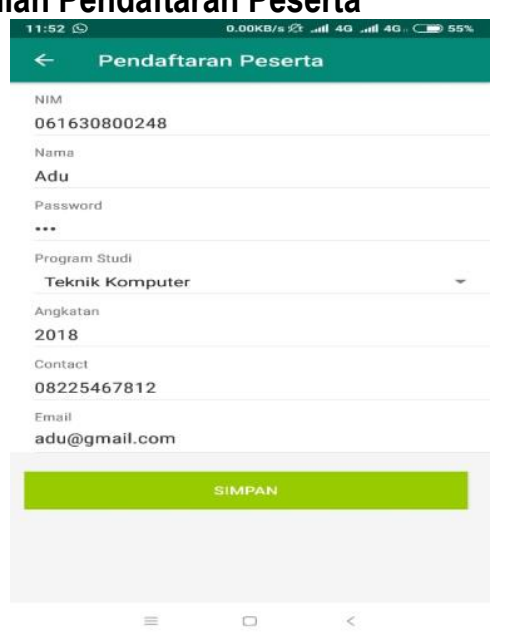

Gambar 5. Tampilan Pendaftaran Peserta

\section{f. Tampilan Tambah Kegiatan}

3) tujuan agar dapat mempermudah admin dalam berbagi informasi kepada anggotanya tentang kegiatan yang akan dilaksanakan oleh setiap Unit Kegiatan Mahasiswa(UKM).

\subsection{Saran}

Berdasarkan beberapa kesimpulan di atas, penulis memberikan beberapa sarany ang dapat dipertimbangkan bagi Perusaahan dalam menangani masalah. Adapun beberapa saran yang penulis sampaikan kepada Unit Kegiatan Mahasiswa (UKM) Politeknik Negeri Sriwijaya Palembang berdasarkan pembahasan yang telah penulis sampaikan pada bab-bab sebelumnya adalah sebagai berikut:

1) Sistem ini masih belumterlalu sempurna,oleh karena itu harus dilakukan perbaikan lagi serta

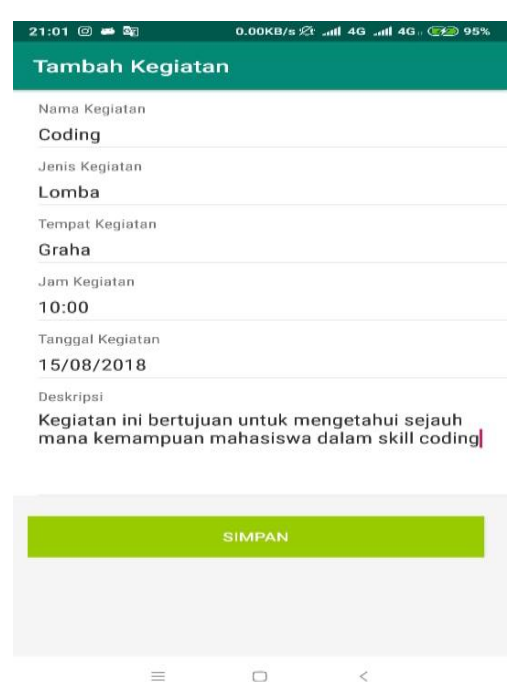

Gambar 5. Tampilan TambahKegiatan

\section{Kesimpulan dan Saran 10.1 Kesimpulan}

Pada bab ini penulis akan menyimpulkan dari keseluruhan pembahasan yang telah penulis sampaikan pada bab-bab sebelumnya. Pada bab ini juga penulis memberikan beberapa saran kepada Ormawa Politeknik Negeri Sriwijaya, dalam mengatasi permasalahan dalam memberikan informasi kegiatan pada anggotanya ,yaitu :

1) Aplikasi kegiatan Ormawa Polsri Berbasis Android ini dibuat dengan menggunakan bahasa Pemrograman Eclipsedengan Dreamweaver dan database MySQL. G

2) Penerapan sistem yang dibuat hanya digunakan untuk internal Unit Kegiatan Mahasiswa(UKM). Politeknik Negeri Sriwijaya Palembang, dengan pembelajaran yang lebih mengenai hal-hal yang berkaitan dengan sistem ini.

2) Sebelum sistem tersebut diimplementasikan dan dioperasikan, sebaiknya diadakan pelatihan terlebih dahulukepada Admin BEM UKM Polsri agar terhindar dari kesalahan atau kekeliruan dalam melakukan proses pengolahan data.

\section{Daftar Pustaka}

A.S, Rosa dan Shalahuddin, M. 2013. Rekayasa Perangkat Lunak Terstruktur dan Berorientasi Objek. Informatika. Bandung

Ariana Azimah,Agus Wibowo,Implementasi Hybrid Mobile Application Berbasis Modular Object Oriented Dynamic Learning Environment Pada 
Adroid dan IOS,Seminar Nasional Teknologi Informasi dan Multimedia,2016 hal 175-180

Rani Puspita,Witta listya Ningrum,Irfan Humaini, Aplikasi Mobile Hijab Berbasis Android, Prociding SNST ke-26,2015 hal 106-111

Sukamto,Rosa,Arini dan M.Shalahuddin (2016) ,Rekayasa Perangkat Lunak Terstruktur Dan Beroerientasi Objek, Bandung, INFORMATIKA

Sutabri,T ( 2012), Analisis Sistem Informasi, Yogyakarta,Andi Offset 